\title{
Usefulness of high-frequency ultrasonography in the assessment of alopecia areata - comparison of ultrasound images with trichoscopic images
}

\author{
Dominik Mikiel ${ }^{1,2}$, Adriana Polańska $^{3}$, Ryszard Żaba ${ }^{3}, Z^{2 y g m u n t ~ A d a m s k i ~}{ }^{1}$, Aleksandra Dańczak-Pazdrowska $^{1}$ \\ ${ }^{1}$ Department of Dermatology, Poznan University of Medical Sciences, Poznan, Poland \\ ${ }^{2}$ Department of Skin Diseases, Provincial Hospital, Poznan, Poland \\ ${ }^{3}$ Department of Dermatology and Venereology, Poznan University of Medical Sciences, Poznan, Poland \\ Adv Dermatol Allergol 2022; XXXIX (1): 132-140 \\ DOI: https://doi.org/10.5114/ada.2020.102641
}

\begin{abstract}
Introduction: Trichoscopy allows us to distinguish between different types of alopecia and to determine the stage of the disease. High-frequency ultrasonography (HF-USG) enables the evaluation of structures that are not available for clinical and trichoscopic examination, but it has not been widely used to date in the evaluation of patients with alopecia areata (AA) and other scalp disorders.

Aim: To characterise the ultrasound images of patients with AA, including different stages of the disease, and to compare them with trichoscopic images and other scalp diseases.

Material and methods: Twenty-five patients with AA, on the basis of trichoscopic examination, were qualified to three groups: with active, inactive, and regrowth phase. Next, HF-USG $(20 \mathrm{MHz})$ with qualitative and quantitative evaluation of various elements of the images was performed: entrance echo (EE), dermis (dermal background; DB), follicular structures (FS), dermal/ subdermal border (D/SB). The results were compared with 10 healthy volunteers, 10 patients with androgenic alopecia (AGA), and 12 with seborrhoeic dermatitis (SebD).

Results: Active AA was characterised by FS with distinct borders, drop-like shaped, with a widened distal end located in the lower layers of DB. Inactive AA was characterised by a smaller number of FS without distinct borders. In the regrowth phase, FS of different widths, elongated, and with widened distal parts located at different DB depths were observed.

Conclusions: HF-USG $(20 \mathrm{MHz})$ may be a valuable diagnostic method in patients with AA. Ultrasound images of AA vary according to the stage of the disease and in comparison with AGA, SebD, and healthy individuals.
\end{abstract}

Key words: alopecia areata, high-frequency ultrasonography, scalp diseases, trichoscopy.

\section{Introduction}

Alopecia is a common problem of patients visiting a dermatologist. Clinically, non-scarring and scarring alopecia can be distinguished. The first form is much more frequent and is a potentially reversible process [1]. The most common types of non-scarring alopecia include telogen effluvium and androgenetic alopecia (AGA), while alopecia areata $(A A)$ is less common [2-5]. The basis for the diagnosis of alopecia, including non-scarring alopecia, are clinical presentation and trichoscopy, while in doubtful situations a biopsy should be taken for histological examination $[6,7]$. Trichoscopy, or dermoscopy of hair and scalp, is a non-invasive diagnostic method in which a hand-held dermoscope or videodermoscope is used to assess various hair disorders [8]. High-frequency ultrasonography (HF-USG) is another non-invasive diagnostic method that has been applied in dermatology for many years [9]; however, its usefulness for the assessment of different forms of alopecia has not been widely investigated; there are only single reports referring to the subject [10-12]. HF-USG provides an evaluation of structures not available for clinical and trichoscopic examination, including hair follicles, which show significantly lower echogenicity than the surrounding structures, and thus may be a valuable complement to the diagnostic methods used so far, as we have shown in our previous studies [13].

Address for correspondence: Dominik Mikiel, Department of Dermatology, Poznan University of Medical Sciences, 49 Przybyszewskiego St, 60-355 Poznan, Poland, phone: +48 669367 197, e-mail: mikielki@gmail.com

Received: 1.11.2020, accepted: 20.11.2020. 


\section{Aim}

The aim of the presented study was to characterise the ultrasound images of patients with AA, taking into account different stages of the disease, and to compare them with trichoscopic images and other diseases of the scalp.

\section{Material and methods}

A total of 57 adults were examined. The study group consisted of 25 patients with AA, including 19 women and 6 men (mean age: $35.7 \pm 14.9,18-84$ years old). The severity of AA was determined according to the Severity of Alopecia Tool (SALT), and its mean value was 55 $\pm 33.8 \%$ [14]. The control groups comprised: 10 healthy volunteers ( 6 women/4 men, mean age $39.4 \pm 13.1 ; 27-59$ years old), 12 patients with seborrhoeic dermatitis (SebD) ( 9 women/3 men; mean age $36.3 \pm 13.2$; 21-66), and 10 patients with AGA ( 2 women/8 men; mean age: $40.9 \pm 15.4$; 25-69). In the study group, 6 patients remained under therapy (2 patients under cyclosporine A, 1 under phototherapy, and 3 under topical diphenylcyclopropenone). The rest of the study group and all of the control groups had not received treatment for hair loss in the preceding 6 months. The inclusion criterion for the AGA group was disease severity at the level IV or higher on the Norwood scale [15]. The exclusion criteria for both the study and control groups were as follows: age under 18 years, pregnancy, and comorbidities. In all the examined patients, the clinical and trichoscopic images provided the grounds for the final diagnosis; therefore, the biopsy for histological examination was abandoned, taking into account the fact that this procedure may exacerbate the stress associated with the underlying disease.

Twenty-five ultrasound images of AA patients were evaluated, of which 3 groups were identified based on trichoscopic features: the group with active phase of the disease (9 persons), inactive phase (7 persons), and with regrowth (9 persons). Thrity-two sonograms of people from control groups were also analysed, including 10 healthy volunteers, 12 with SebD, and 10 with AGA.

The study was divided into two steps. In the first part, each patient underwent a trichoscopic examination in two versions: the so-called dry trichoscopy - without the immersion fluid and the so-called wet trichoscopy with immersion fluid (Kodan Tinktur Forte). The tests were performed in the parietal area, $2-3 \mathrm{~cm}$ lateral to the midline of the body. The trichoscopic examination was performed with the use of a Fotofinder Dermoscope Medicam $800 \mathrm{HD}$ with the possibility of image magnification from 20x to 50x, including saving and archiving the images. In trichoscopy of AA patients, the presence of broken hairs, micro-exclamation mark hairs, and black dots qualified to the active AA. Finding only yellow dots and vellus hairs qualified to the inactive AA, while the presence of upright regrowing hairs, circular hairs (pigtail hairs), and terminal hairs with/without pigment qualified to the regrowth phase [16]. In the second stage, HF-USG was performed in the same location as the trichoscopic examination. HFUSG was carried out using a linear probe transverse to the midline of the body, covered with a layer of ultrasound gel, about $1 \mathrm{~mm}$ thick. In order to prepare the patient for the examination, in case of hair presence the hair was shaved to the level of the skin in a circle-shaped area of $2 \mathrm{~cm}$ diameter to eliminate acoustic shadows of hair shafts, which would hinder later interpretation of ultrasound images. The choice of the study site was related to the ease of performance, as well as practical and aesthetic considerations, especially for the control group patients. The images were visualised in presentation B (brightness) and then saved. Four elements were assessed during the study: the entrance echo (EE), the dermis (hereinafter the dermal background; DB), the structures corresponding to the hair follicles (hereinafter the follicular structures; FS), and the boundary of the dermis and subcutaneous tissue (hereinafter the dermal/subdermal border; D/SB). Appropriate measurements were made in individual elements: EE - thickness, DB - thickness (measured from the upper border of EE to the lower border of DB) and echogenicity, FS - length (from the lower border of EE to the distal end of the FS in layers of DB), width (in the widest section of the visible FS), echogenicity, and number of FS. The FS boundaries were qualitatively clear or not clear. Additionally, the morphological description of particular elements of ultrasound images was also made. HF-USG was performed with the Dermascan C Cortex Technology (Denmark) linear probe with a frequency of $20 \mathrm{MHz}$, allowing penetration to a depth of $10 \mathrm{~mm}$, with axial and lateral resolution of 80 and $200 \mu \mathrm{m}$, respectively, combined with specialised DermaScan software that allows for saving and archiving images, and making the necessary measurements.

\section{Statistical analysis}

The obtained results were statistically analysed using the SPSS Statistics version 26 software. The mean values of the tested parameters with standard deviations were determined, as well as the minimum and maximum values. The differences between the results were determined based on the ANOVA analysis. Then, Duncan's post hoc test was used to characterise the differences between the groups. $P<0.05$ was considered as statistically significant. Additionally, the level of dependence between trichoscopic and ultrasound images was analysed by determining the Pearson's contingency coefficient.

The research was approved by the local Bioethics Committee (UMP Resolution No. 508/16).

\section{Results}

\section{Ultrasound results}

FS among patients with active AA were in all cases (9/9) with clear borders, with a widened distal end locat- 

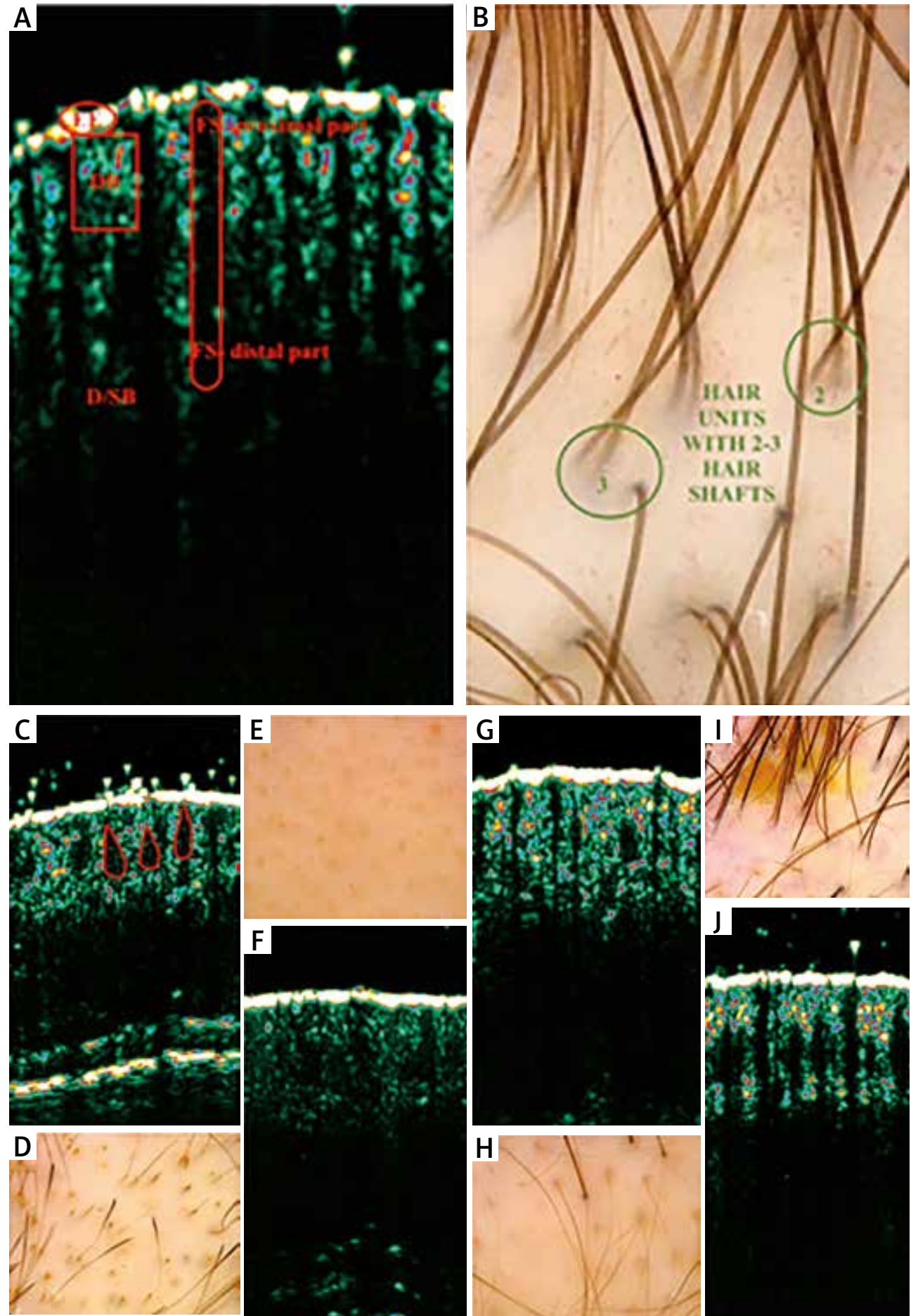

Figure 1. Ultrasound and trichoscopic (20x/50x magnification) images of the parietal region in healthy individuals $(A, B)$, patients with active (C, D) and inactive (E, F) stage of alopecia areata (AA), androgenetic alopecia (AGA) (G, H), and seborrhoeic dermatitis (SebD) (I, J). In the ultrasound image, the following can be distinguished: entrance echo (EE) (red ellipse), dermal background (DB) (red rectangle), dermal/subdermal border (D/SB), follicular structures (FS) with proximal and distal end (longitudinal red structure) (A). Drop-like shaped FS observed in active AA (C). FS without clear boundaries and widened distal parts in inactive AA (F). FS with noticeable width diversity, distal sections located at different levels of the skin in AGA (G). FS with clear borders and dilated distal ends penetrating into the subcutaneous tissue in SebD (J) 
ed in the lower layers of DB, drop-like shaped. In inactive AA, FS without clear boundaries were observed in $57 \%$ (4/7), with clear boundaries in 43\% (3/7), all with a widened distal end located as in the active phase (Figures 1 C, F). In the group with signs of regrowth, FS were found to be of various widths, elongated, and with widened distal segments reaching the middle and deeper layers of DB or penetrating the subcutaneous tissue.

The SebD group was dominated by FS with clear borders of $100 \%(12 / 12)$, with dilated distal ends penetrating into the subcutaneous tissue (Figure $1 \mathrm{~J}$ ).

Among the images of AGA patients, the following features of FS were observed in 100\% (10/10): clear boundaries, noticeable width diversity, distal sections located at different levels of the skin (FS with distal end located in the middle or lower part of the skin and FS penetrating into the subcutaneous tissue) (Figure $1 \mathrm{G}$ ).

In healthy volunteers, FS were distinct, elongated, without dilated fragments, with the distal segments penetrating the subcutaneous tissue (Figure $1 \mathrm{~A}$ ).

FS in HF-USG in all subjects showed lower echogenicity compared to DB both qualitatively and quantitatively.

DB in the majority of analysed sonograms was homogenous throughout its thickness. The exception was the sonograms of patients with AGA and healthy volunteers, where the dominant DB image was an area of varied echogenicity, in the upper part with slightly higher echogenicity than in the lower part, which was observed in $90 \%(9 / 10)$ of patients with AGA and in all healthy volunteers.

D/SB was clear in all cases with active AA (100\%, 9/9), in 44\% with regrowth (4/9), and in 30\% with inactive phase $(2 / 7)$. Blurred D/SB was found in the remaining 56\% (5/9) of regrowth and $70 \%(5 / 7)$ of inactive phase. In SebD, D/SB was clear in the majority of cases, and in the minority of cases blurred - in 92\% (11/12) and $8 \%(1 / 12)$, respectively. In AGA, clear D/SB was observed in $70 \%(7 / 10)$ and blurred in 30\% (3/10) of cases. Among healthy volunteers, D/SB was clear in all cases.

The mean values of the analysed ultrasound parameters in particular groups are presented in Tables 1-4. Measurements of FS length among healthy volunteers and SebD were not possible due to penetration of distal FS into subcutaneous tissue in these groups and the same echogenicity of FS and subcutaneous tissue, which resulted in the inability to visualise the distal segment.

\section{Trichoscopic results}

The most common trichoscopic structures observed in the AA group were yellow dots $96 \%$ (24/25), followed by broken hairs 52\% (13/25), black dots 48\% (12/25), micro-exclamation mark hairs 36\% (9/25), further new terminal hairs without pigment 32\% (8/25), upright regrowing hairs 24\% (6/25), and vellus hairs 20\% (5/25).

Among patients with SebD, the dominant trichoscopic structures were yellowish areas $83 \%$ (10/12), white scale $75 \%$ (9/12) and yellow scale 50\% (6/12), vessels most often of the thin arborising type $50 \%(6 / 12)$, and

Table 1. The mean values of analysed ultrasound parameters in different groups of examined patients

\begin{tabular}{|c|c|c|c|c|c|c|c|c|}
\hline $\begin{array}{l}\text { Ultrasound } \\
\text { parameter }\end{array}$ & $\begin{array}{l}\text { Healthy } \\
\text { individuals } \\
(n=10)\end{array}$ & $\begin{array}{l}\text { Total AA } \\
\text { patients } \\
(n=25)\end{array}$ & $\begin{array}{l}\text { AA active } \\
\text { patients } \\
(n=9)\end{array}$ & $\begin{array}{l}\text { AA inactive } \\
\text { patients } \\
(n=7)\end{array}$ & $\begin{array}{l}\text { AA regrowth } \\
\text { patients } \\
(n=9)\end{array}$ & $\begin{array}{l}\text { SebD } \\
\text { patients } \\
(n=12)\end{array}$ & $\begin{array}{c}\text { AGA } \\
\text { patients } \\
(n=10)\end{array}$ & $\frac{0}{\frac{0}{2}}$ \\
\hline $\begin{array}{l}\text { EE thickness, mean } \\
\pm \mathrm{SD}[\mathrm{mm}]\end{array}$ & $0.198 \pm 0.024$ & $0.199 \pm 0.021$ & $0.206 \pm 0.015$ & $0.185 \pm 0.026$ & $0.204 \pm 0.023$ & $0.185 \pm 0.020$ & $0.199 \pm 0.016$ & 0.129 \\
\hline $\begin{array}{l}\text { Skin thickness, mean } \\
\pm \mathrm{SD}[\mathrm{mm}]\end{array}$ & $2.187 \pm 0.244$ & $2.340 \pm 0.221$ & $2.369 \pm 0.228$ & $2.302 \pm 0.249$ & $2.341 \pm 0.249$ & $\begin{array}{c}2.039 \\
\pm 0.248\end{array}$ & $2.299 \pm 0.252$ & 0.014 \\
\hline $\begin{array}{l}\text { Skin echogenicity (with } \\
\mathrm{EE}), \text { mean } \pm \mathrm{SD}(\%)\end{array}$ & $6.55 \pm 0.32$ & $6.93 \pm 0.37$ & $7.03 \pm 0.14$ & $6.84 \pm 0.50$ & $6.90 \pm 0.42$ & $6.73 \pm 0.33$ & $6.63 \pm 0.42$ & 0.135 \\
\hline $\begin{array}{l}\text { Skin echogenicity } \\
\text { (without EE), mean } \\
\pm \text { SD (\%) }\end{array}$ & $6.48 \pm 0.32$ & $6.89 \pm 0.37$ & $6.99 \pm 0.15$ & $6.83 \pm 0.52$ & $6.84 \pm 0.39$ & $6.69 \pm 0.36$ & $6.60 \pm 0.41$ & 0.147 \\
\hline $\begin{array}{l}\text { Number of FS, mean } \\
\pm \mathrm{SD}\end{array}$ & $10.2 \pm 0.8$ & $8.8 \pm 1.5$ & $9.1 \pm 1.6$ & $8.6 \pm 1.8$ & $8.7 \pm 1.3$ & $10.1 \pm 0.9$ & $8.8 \pm 1.3$ & 0.146 \\
\hline $\begin{array}{l}\text { Width of FS, mean } \\
\pm \mathrm{SD}[\mathrm{mm}]\end{array}$ & $0.703 \pm 0.210$ & $0.902 \pm 0.246$ & $1.048 \pm 0.220$ & $0.953 \pm 0.144$ & $0.715 \pm 0.286$ & $0.786 \pm 0.160$ & $0.472 \pm 0.071$ & $<0.001$ \\
\hline $\begin{array}{l}\text { Length of FS, mean } \\
\pm S D[\mathrm{~mm}]\end{array}$ & $\mathrm{n} / \mathrm{b}$ & $1.196 \pm 0.179$ & $1.259 \pm 0.192$ & $1.204 \pm 0.182$ & $1.127 \pm 0.184$ & $\mathrm{n} / \mathrm{b}$ & $1.313 \pm 0.123$ & 0.517 \\
\hline $\begin{array}{l}\text { FS echogenicity, mean } \\
\pm \mathrm{SD}[\mathrm{mm}]\end{array}$ & $5.52 \pm 0.39$ & $6.14 \pm 0.38$ & $6.13 \pm 0.27$ & $6.09 \pm 0.49$ & $6.19 \pm 0.52$ & $5.72 \pm 0.23$ & $5.61 \pm 0.21$ & $<0.001$ \\
\hline
\end{tabular}

EE - entrance echo, FS - follicular structures, AA - alopecia areata, SebD - seborrheic dermatitis, AGA - androgenetic alopecia. 
Table 2. $P$-value in Duncan's post hoc test. Skin thickness in the study and control groups

\begin{tabular}{lccccccc}
\hline Group & $\begin{array}{c}\text { Healthy individuals } \\
(n=10)\end{array}$ & $\begin{array}{c}\text { AA total } \\
(n=25)\end{array}$ & $\begin{array}{c}\text { AA active } \\
(n=9)\end{array}$ & $\begin{array}{c}\text { AA inactive } \\
(n=7)\end{array}$ & $\begin{array}{c}\text { AA regrowth } \\
(n=9)\end{array}$ & $\begin{array}{c}\text { SebD } \\
(n=12)\end{array}$ & $\begin{array}{c}\text { AGA } \\
(n=10)\end{array}$ \\
\hline $\begin{array}{l}\text { Healthy individuals } \\
(n=10)\end{array}$ & - & 0.207 & 0.148 & 0.324 & 0.210 & 0.190 & 0.313 \\
\hline $\begin{array}{l}\text { AA total } \\
(n=25)\end{array}$ & 0.207 & - & 0.803 & 0.727 & 0.992 & 0.024 & 0.721 \\
\hline $\begin{array}{l}\text { AA active } \\
(n=9)\end{array}$ & 0.148 & 0.803 & - & 0.571 & 0.801 & 0.017 & 560 \\
\hline $\begin{array}{l}\text { AA inactive } \\
(n=7)\end{array}$ & 0.324 & 0.727 & 0.572 & - & 0.732 & 0.041 & 0.980 \\
\hline $\begin{array}{l}\text { AA regrowth } \\
(n=9)\end{array}$ & 0.210 & 0.992 & 0.801 & 0.732 & - & 0.025 & 0.720 \\
\hline $\begin{array}{l}\text { SebD } \\
(n=12)\end{array}$ & 0.190 & 0.024 & 0.017 & 0.041 & 0.025 & - & 0.039 \\
\hline $\begin{array}{l}\text { AGA } \\
(n=10)\end{array}$ & 0.313 & 0.721 & 0.560 & 0.980 & 0.720 & 0.039 \\
\hline
\end{tabular}

Table 3. $P$-value in Duncan's post hoc test. Width of follicular structures (FS) in the study and control groups

\begin{tabular}{lccccccc}
\hline Group & $\begin{array}{c}\text { Healthy individuals } \\
(n=10)\end{array}$ & $\begin{array}{c}\text { AA total } \\
(n=25)\end{array}$ & $\begin{array}{c}\text { AA active } \\
(n=9)\end{array}$ & $\begin{array}{c}\text { AA inactive } \\
(n=7)\end{array}$ & $\begin{array}{c}\text { AA regrowth } \\
(n=9)\end{array}$ & $\begin{array}{c}\text { SebD } \\
(n=12)\end{array}$ & $\begin{array}{c}\text { AGA } \\
(n=10)\end{array}$ \\
\hline $\begin{array}{l}\text { Healthy individuals } \\
(n=10)\end{array}$ & - & 0.042 & 0.002 & 0.015 & 0.883 & 0.343 & 0.015 \\
\hline $\begin{array}{l}\text { AA total } \\
(n=25)\end{array}$ & 0.042 & - & 0.110 & 0.533 & 0.048 & 0.180 & $<0.001$ \\
\hline $\begin{array}{l}\text { AA active } \\
(n=9)\end{array}$ & 0.002 & 0.110 & - & 0.264 & 0.003 & 0.011 & $<0.001$ \\
\hline $\begin{array}{l}\text { AA inactive } \\
(n=7)\end{array}$ & 0.015 & 0.533 & 0.264 & - & 0.018 & 0.073 & $<0.001$ \\
\hline $\begin{array}{l}\text { AA regrowth } \\
(n=9)\end{array}$ & 0.883 & 0.048 & 0.003 & 0.018 & - & 0.393 & 0.014 \\
\hline $\begin{array}{l}\text { SebD } \\
(n=12)\end{array}$ & 0.343 & 0.180 & 0.011 & 0.073 & 0.393 & - & 0.004 \\
\hline $\begin{array}{l}\text { AGA } \\
(n=10)\end{array}$ & 0.015 & $<0.001$ & $p<0.001$ & $<0.001$ & 0.014 & 0.004 & - \\
\hline
\end{tabular}

Table 4. $P$-value in Duncan's post hoc test. Follicular structures (FS) echogenicity in the study and control groups

\begin{tabular}{lccccccc}
\hline Group & $\begin{array}{c}\text { Healthy individuals } \\
(n=10)\end{array}$ & $\begin{array}{c}\text { AA total } \\
(n=25)\end{array}$ & $\begin{array}{c}\text { AA active } \\
(n=9)\end{array}$ & $\begin{array}{c}\text { AA inactive } \\
(n=7)\end{array}$ & $\begin{array}{c}\text { AA regrowth } \\
(n=9)\end{array}$ & $\begin{array}{c}\text { SebD } \\
(n=12)\end{array}$ & $\begin{array}{c}\text { AGA } \\
(n=10)\end{array}$ \\
\hline $\begin{array}{l}\text { Healthy individuals } \\
(n=10)\end{array}$ & - & 0.001 & 0.001 & 0.001 & $<0.001$ & 0.139 & 0.446 \\
\hline $\begin{array}{l}\text { AA total } \\
(n=25)\end{array}$ & 0.001 & - & 0.954 & 0.689 & 0.700 & 0.009 & 0.002 \\
\hline $\begin{array}{l}\text { AA active } \\
(n=9)\end{array}$ & 0.001 & 0.954 & - & 0.717 & 0.673 & 0.008 & 0.002 \\
\hline $\begin{array}{l}\text { AA inactive } \\
(n=7)\end{array}$ & 0.001 & 0.689 & 0.717 & - & 0.458 & 0.013 & 0.003 \\
\hline $\begin{array}{l}\text { AA regrowth } \\
(n=9)\end{array}$ & $<0.001$ & 0.700 & 0.673 & 0.458 & - & 0.005 & 0.001 \\
\hline $\begin{array}{l}\text { SebD } \\
(n=12)\end{array}$ & 0.139 & 0.009 & 0.008 & 0.013 & 0.005 & - & 0.397 \\
\hline $\begin{array}{l}\text { AGA } \\
(n=10)\end{array}$ & 0.446 & 0.002 & 0.002 & 0.003 & 0.001 & 0.397 & - \\
\hline
\end{tabular}


multicomponent (more than two types) 50\% (6/12); the least frequent were yellow dots, at 8\% (1/12).

In $100 \%(10 / 10)$ of patients in the AGA group yellow dots, vellus hairs, clear differences in the thickness of hair shafts, and increased number of hair units with only single hair shaft were found.

Trichoscopic images in healthy volunteers consisted of regular follicular openings with hair units consisting mainly of three or two hair shafts.

A summary of the trichoscopic features and ultrasound images of FS for active $A A$, inactive $A A$ and regrowth stage of AA, SebD, AGA, and healthy volunteers is presented in Table 5.

Comparing the obtained trichoscopic images with the ultrasound images of patients with AA based on the Pearson contingency coefficient, a clear, statistically significant relationship was obtained between the analysed variables $(c=0.739, p<0.001)$ (shown in Table 5).

\section{Discussion}

HF-USG images in healthy volunteers showed in each case: clearly marked hyperechoic (in relation to DB) entrance echo (EE), a clear band corresponding to the dermis (DB), with clear, hypoechoic FS in the mean number of $10.2 \pm 0.8$ arranged perpendicularly or obliquely to the EE line, with no visible distal end which penetrated into the subcutaneous tissue and did not differ in echogenicity, with an average width of $0.703 \pm 0.210 \mathrm{~mm}$, and with the hypoechoic layer corresponding to the subcutaneous tissue. The border between skin and subcutaneous tissue (D/SB) was clear, dominated by distal segments of FS (Figure $1 \mathrm{~A}$ ). Such a picture was also described in our previous research [13].

The ultrasound parameters analysed in AA patients in comparison with healthy volunteers showed statistically significant differences in the width and echogenicity of FS. The problem of FS length, despite the lack of significant differences between the studied groups, requires wider discussion.

FS in patients with active and inactive AA was significantly wider than in the healthy group $(p=0.002$ and $p=0.015$, respectively). The FS width in the regrowth group was not significantly greater than that observed in healthy volunteers $(p=0.883)$. Mean values of FS width were the highest in active AA $(1.048 \pm 0.220 \mathrm{~mm})$, then inactive $A A(0.953 \pm 0.144 \mathrm{~mm})$, and the smallest in patients with the regrowth $(0.715 \pm 0.286 \mathrm{~mm})$. This seems to be one of the main features differentiating FS images between healthy and AA patients. These results confirm earlier observations of El-Zawahry et al. who found statistically significant differences between the width of hair follicles in patients with AA from the affected areas as compared to the areas without the lesions [11]. This may

Table 5. Comparison of ultrasound images of follicular structures (FS) with trichoscopic images in different stages of alopecia areata and in control groups

\begin{tabular}{|c|c|c|}
\hline Disease & Ultrasound (typical FS) & Trichoscopy \\
\hline \multirow[t]{4}{*}{ Alopecia areata (active stage) } & Distinct, drop-like shaped & Black dots \\
\hline & Distal part in lower dermal region & Micro- exclamation mark hairs \\
\hline & & Broken hairs \\
\hline & & Yellow dots \\
\hline \multirow[t]{3}{*}{ Alopecia areata (inactive stage) } & Usually not distinct, reduced number & Yellow dots \\
\hline & With widened distal part & Vellus hairs \\
\hline & Distal part in lower dermal region & \\
\hline \multirow[t]{5}{*}{ Alopecia areata (regrowth stage) } & Distinct & Upright regrowing hairs \\
\hline & Width diversity & Pigtail hairs \\
\hline & Distal parts on different levels of the skin & Vellus hairs \\
\hline & (heterogeneity) also & Terminal hairs with/without pigment \\
\hline & penetrate into subdermal layer & \\
\hline \multirow[t]{5}{*}{ Seborrhoeic dermatitis } & Distinct, with widened distal parts & Yellowish areas \\
\hline & Distal parts penetrate into subdermal layer & White scale \\
\hline & & Yellow scale \\
\hline & & Thin arborizing vessels \\
\hline & & Multicomponent vessels \\
\hline \multirow[t]{4}{*}{ Androgenetic alopecia } & Distinct & Yellow dots \\
\hline & Width diversity & Vellus hairs \\
\hline & Distal parts on different levels of the skin & Hair shafts thickness diversity \\
\hline & (heterogeneity) & Increased number of single hair shaft units \\
\hline \multirow[t]{2}{*}{ Healthy individuals } & Distinct & Regular hair units with two or three hair shafts \\
\hline & $\begin{array}{l}\text { Elongated distal parts penetrate into } \\
\text { subdermal layer }\end{array}$ & \\
\hline
\end{tabular}


be associated with the presence of intensive inflammatory infiltration within the lower parts of hair follicles in the active form of AA [17]. Additionally, it should be noted that the symptom of extended FS does not occur only in the active form of AA and may be seen in other diseases such as hidradenitis suppurativa characterised by intense inflammation [18]. The width of FS in AA patients, regardless of the disease stage, was also greater than observed in AGA patients. It is worth noting that the width of FS in the AGA group was the smallest of all the studied groups. It can be associated with the process of hair follicle miniaturisation in the course of AGA [19]. In contrast to our observations, Wortsman et al. did not observe any significant differences in the width of the hair follicles measured by ultrasound between healthy and AGA patients in the frontal region of the scalp [12]. These differences may result from a more advanced disease process among our patients with AGA ( $\geq$ IV Norwood scale) and the assumption that the structures visible in HF-USG are not individual hair follicles but overlapping echoes of several hair follicles forming units (in AGA there is a miniaturisation of single follicles as well as a reduction in the number of terminal hairs in favour of vellus hairs in particular follicular units) [19]. The width of FS in patients with SebD was significantly smaller only in comparison with the active form of AA, while significantly greater only in relation to $A G A$.

The echogenicity of FS was significantly higher in each group of AA compared to healthy, SebD and AGA patients. The highest mean echogenicity of FS was found in the regrowth group $(6.19 \pm 0.52 \%)$, then in active AA $(6.13 \pm 0.27 \%)$, and the lowest in the inactive form of AA $(6.09 \pm 0.49 \%)$. The differences between the AA groups were not statistically significant. The greater echogenicity of FS in AA patients is the surprising observation that, as shown in a number of previous studies, the inflammatory infiltration in the tissue results in a reduction of the echogenicity of ultrasound images. This was confirmed by the correlation of HF-USG and histological images, e.g. in the works of Polańska et al. with regard to cutaneous lymphomas [20-22], psoriasis [23], or atopic dermatitis [24]. In relation to the scalp, the influence of the hair itself on the echogenicity of the examined structures can be additionally considered. Perhaps the normal hair present in the hair follicles reduces the echogenicity of FS. Conversely, damage to the hair structure by inflammatory cells, ultimately causing it to fall out and increasing the number of empty hair follicles, potentially results in increased echogenicity. Of course, this hypothesis requires further research, taking into account the correlation of histological and ultrasound images. Echogenicity of FS in SebD and AGA were not significantly different from healthy volunteers $(p=0.139$ and $p=0.446$, respectively). Comparing the echogenicity of FS in the SebD and AGA groups, also no significant differences were found $(p=0.397)$.
When analysing the FS length among the examined patients, three types of common HF-USG images should be distinguished: FS visible on the entire thickness of the skin with no visible distal end, which was characteristic of healthy volunteers and SebD; then, FS with a widened distal end located in the deeper areas of the skin characteristic of active and inactive AA; and the third observed picture is the significant heterogeneity of the FS length. In this case, the coexistence of FS with distal ends located within the middle/lower layers of the skin along with FS penetrating into the subcutaneous tissue was found. Such an image concerned sonograms of patients with AA in the regrowth phase and AGA patients. It should be assumed that the differentiation of HF-USG images in relation to the FS length should be based on a descriptive assessment and not on specific values of FS length.

On the other hand, the thickness of the skin was highest in active AA (mean: $2.369 \pm 0.228 \mathrm{~mm}$ ), lower in total AA patients (mean: $2.340 \pm 0.221 \mathrm{~mm}$ ), and in inactive AA (mean: $2.302 \pm 0.249 \mathrm{~mm}$ ), while the lowest was seen among healthy volunteers (mean: $2.187 \pm 0.244$ $\mathrm{mm}$ ); the differences were not statistically significant. It seems that the obtained differences may result from the possibility of visualising the lower border of the skin in particular situations. The more pronounced the distal end of FS that does not penetrate into the subcutaneous tissue, the greater the possibility of precisely visualising the lower border of the skin. The mean skin thickness in SebD $(2.039 \pm 0.248 \mathrm{~mm})$ was significantly smaller compared to the groups with AA $(p<0.05)$ and AGA ( $p=$ 0.039 ) and was the closest to the healthy group, which is probably due to the previously discussed difference in the possibility of visualising the lower border of the skin.

The analysed parameter values, such as: the thickness of EE, the echogenicity of the skin measured with/ without $E E$, and the number of FS, did not show any significant differences between compared groups. However, it is worth noting a certain tendency observed in our study, i.e. in healthy volunteers, the mean number of FS $(10.2 \pm 0.8)$ was higher than that obtained in active AA (9.1 $\pm 1.6)$ and inactive $A A(8.6 \pm 1.8)$. This can be explained by the fact that, as shown in the histological examination of skin sections of AA patients, one should expect a predilection to reduce the number of hair follicles along with the duration of the disease process [17].

The trichoscopic patterns of healthy volunteers, patients with $A A$, SebD, and AGA differed from each other; moreover, the AA images differed depending on the phase of the disease. The characteristic trichoscopic structures have been accurately and repeatedly presented in the available literature [16, 25-27]. The images we obtained corresponded with those described in the literature.

A pioneering observation resulting from our research is to demonstrate that HF-USG images of patients with $A A$, as well as trichoscopic images, differed depending 
on the phase of the disease. Based on the results, it seems that for the active AA, black dots, broken hairs, and micro-exclamation hairs present in trichoscopy will correspond to clear, widened FS with morphology resembling water drops. The inactive phase, in trichoscopy with dominant yellow dots, in HF-USG corresponds mainly FS without clear boundaries. The number of occurring FS are lower compared to healthy volunteers. It seems important to pay attention to the group of patients with yellow dots visible in trichoscopy, who presented FS similar to normal in HF-USG, which may be associated with upcoming regrowth. The presented image may be a prognostic factor; however, it requires further studies on a larger group of patients. The regrowth phase corresponds to the presence of typical structures observed in healthy individuals - longitudinal FS without visible distal end but also thin FS with a distinct distal end, in trichoscopy - vellus hairs.

An interesting observation concerns the studied patients with AA during cyclosporin A therapy (2 patients) and phototherapy (1 patient), who finally did not achieve a sustained clinical response after the treatment cycle. Among the analysed 3 cases, within individual sonograms, the coexistence of HF-USG features relating to different phases of the disease was observed. FS were found with morphology similar to the regrowth phase along with FS typical of the active or inactive stage of AA. Perhaps such a picture may be a bad prognostic factor.

A special ultrasound image was also obtained among patients with advanced forms of AGA (Norwood IV and higher). The irregular arrangement of the FS and their distal ends located at different depths of DB were observed. It may be related to the increased number of telogen and miniaturised hairs in patients with AGA [28]. These differences may be particularly useful in the difficult clinical situations we encounter in patients with diffuse AA, which may be clinically similar to AGA. It should be noted that the use of HF-US in such potentially reduces the need for a biopsy.

The presented results are one of the first analyses documenting that HF-USG $(20 \mathrm{MHz})$ may be a valuable diagnostic method in patients with AA. In the authors' opinion, HF-USG allows us to distinguish between the active, inactive, and regrowth phase, which is undoubtedly important from the prognostic and psychological point of view for patients who are afraid of permanent hair loss. Moreover, the study showed that the ultrasound images in different types of non-scarring alopecia may differ from each other, which was proven especially on the example of AA and AGA. The main features of the HF-USG images differentiating the particular AA phases, as well as AA and other physiological and pathological conditions discussed in this paper, were FS length, width, and echogenicity. It should be emphasised that the obtained images are not sufficiently characteristic to enable an unambiguous diagnosis, and in doubtful situations biopsy with histological examination is still the gold standard of diagnosis. HF-USG may, however, constitute a valuable supplement to the techniques used so far, such as trichoscopy, especially due to its non-invasive nature and thus the possibility of using it in the paediatric population. At the same time, the authors are aware of some limitations of the study. First, the HF-USG images should be correlated with the histological ones. It would also be necessary to extend the analysis to other forms of nonscarring alopecia, e.g. trichotillomania or alopecia in the course of systemic lupus erythematosus (SLE).

\section{Conflict of interest}

The authors declare no conflict of interest.

\section{References}

1. Bernardez C, Molina-Ruiz AM, Requena L. Histologic features of alopecias-part I: nonscarring alopecias. Actas Dermosifiliogr 2015; 106: 158-67.

2. Hordinsky MK. Medical treatment of noncicatricial alopecia. Semin Cutaneous Med Surg 2006; 25: 51-5.

3. Lolli F, Pallotti F, Rossi A, et al. Androgenetic alopecia: a review. Endocrine 2017; 57: 9-17.

4. Wolff H, Fischer TW, Blume-Peytavi U. The diagnosis and treatment of hair and scalp diseases. Dtsch Arztebl Int 2016; 113: 377-86.

5. Strazzulla LC, Wang EHC, Avila L, et al. Alopecia areata: disease characteristics, clinical evaluation, and new perspectives on pathogenesis. J Am Acad Dermatol 2018; 78: 1-12.

6. Mubki T, Rudnicka L, Olszewska M, Shapiro J. Evaluation and diagnosis of the hair loss patient: part I. History and clinical examination. J Am Acad Dermatol 2014; 71: 415.e1-15.

7. Mubki T, Rudnicka L, Olszewska M, Shapiro J. Evaluation and diagnosis of the hair loss patient: part II. Trichoscopic and laboratory evaluations. J Am Acad Dermatol 2014; 71: 431. e1-11.

8. Otberg N, Shapiro J, Lui H, et al. Scalp imaging techniques. Laser Physics Letters 2017; 14: 055701.

9. Alexander H, Miller DL. Determining skin thickness with pulsed ultrasound. J Invest Dermatol 1979; 72: 17-9.

10. Lázaro-Simó Al, Sancho MI, Quintana-Codina M, et al. Alopecic and aseptic nodules of the scalp with trichoscopic and ultrasonographic findings. Indian J Dermatol 2017; 62: 515-8.

11. El-Zawahry BM, El Hanafy M, Bassiouny DA, et al. In vivo visualization of hair follicles by ultrasound biomicroscopy in alopecia areata and its correlation with histopathology. Acta Dermatovenerol Croat 2015; 23: 12-8.

12. Wortsman X, Guerrrero R, Wortsman J. Hair morphology in androgentic alopecia. J Ultrasound Med 2014; 33: 1265-72.

13. Mikiel D, Polańska A, Żaba R, et al. High-frequency ultrasonography of the scalp - comparison of ultrasound and trichoscopic images in healthy individuals. Skin Res Technol 2019; 25: 720-4.

14. Olsen EA, Hordinsky MK, Price VH, et al.; National Alopecia Areata Foundation (2004). Alopecia areata investigational assessment guidelines--Part II. National Alopecia Areata Foundation. J Am Acad Dermatol 2004; 51: 440-7.

15. Norwood OT. Male pattern baldness: classification and incidence. South Med J 1975; 68: 1359-65. 
16. Rudnicka L, Olszewska M, Rakowska A, Czuwara J. Alopecia areata. In: Atlas of Trichoscopy: Dermoscopy in Hair and Scalp Disease. Rudnicka L, Olszewska M, Rakowska A (eds). Springer, London 2012, 205-6.

17. Whiting DA. Histopathologic features of alopecia areata: a new look. Arch Dermatol 2003; 139: 1555-9.

18. Wortsman X. Common applications of dermatologic sonography. J Ultrasound Med 2012; 31: 97-111.

19. Sellheyer K, Bergfeld WF. Histopathologic evaluation of alopecias. Am J Dermatopathol 2006; 28: 236-59.

20. Polańska A, Osmola-Mańkowska A, Olek-Hrab K, et al. Highfrequency ultrasonography in objective evaluation of the efficacy of PUVA and UVA 1 phototherapy in mycosis fungoides. Arch Dermatol Res 2017; 309: 645-51.

21. Polańska A, Bowszyc-Dmochowska M, Olek-Hrab K, et al. High-frequency ultrasonography a new quantitative method in evaluation of skin lymphomas - first comparative study in relation to histopathology. Skin Res Technol 2018; 24: 517-21.

22. Polańska A, Dańczak-Pazdrowska A, Olek-Hrab K, et al. Highfrequency ultrasonography-New non-invasive method in assessment of skin lymphomas. Skin Res Technol 2018; 24: 517-21.

23. Polańska A, Gaura T, Bowszyc-Dmochowska M, et al. Calcipotriol/betamethasone ointment compared to narrow-band UVB in plaque psoriasis: first clinical and ultrasonographic study. Int J Dermatol 2019; 58: 108-13.

24. Polańska A, Dańczak-Pazdrowska A, Silny W, et al. Comparison between high-frequency ultrasonography (Dermascan C, version 3) and histopathology in atopic dermatitis. Skin Res Technol 2013; 19: 432-7.

25. Inui S, Nakajima T, Nakagawa K, Itami S. Clinical significance of dermoscopy in alopecia areata: analysis of 300 cases. Int J Dermatol 2008; 47: 688-93.

26. Waśkiel A, Rakowska A, Sikora M, et al. Trichoscopy of alopecia areata: an update. J Dermatol 2018; 45: 692-700.

27. Widaty S, Pusponegoro EH, Rahmayunita G, et al. Applicability of trichoscopy in scalp seborrheic dermatitis. Int J Trichol 2019; 11: 43-8.

28. El-Domyati M, Attia S, Saleh F, Abdel-Wahab H. Androgenetic alopecia in males: a histopathological and ultrastructural study. J Cosmet Dermatol 2009; 8: 83-91. 